\title{
The Research on Characteristic Database Construction of the Ethnic Universities in China
}

\author{
Jun $\mathrm{Ma}^{1}$ \\ ${ }^{1}$ School of Modern Education Technology, Northwest University for Nationalities, Lanzhou, China \\ Correspondence: Jun Ma, Associate Professor, School of Modern Education Technology, Northwest University for \\ Nationalities, Lanzhou 730124, China. E-mail: 364221500@qq.com
}

Received: August 5, 2015

Accepted: August 11, 2015

Online Published: August 16, 2015

doi:10.5430/jms.v6n3p44

URL: http://dx.doi.org/10.5430/jms.v6n3p44

This work was supported by the Fundamental Research Funds for the Central Universities of Northwest University for Nationalities (Grant No.ZYZ2012041).

\begin{abstract}
This paper selects the representative ethnic university in China by using the method of humanistic study and analyses of Chinese educational resources in universities for nationalities so as to get research of focus and direction in this area in recent years. At the same time, the paper analyzes the causes and solutions for the existing problems contributing to the special education resources construction of database in universities for nationalities.
\end{abstract}

Keywords: characteristic database, ethnic universities, ethnic education

\section{Introduction}

Teaching resource library is built in accordance with international standards, by knowledge of digital material and representation of basic materials such as teaching case of open teaching system. Teaching resource database includes resource collection, checking, retrieval, browsing, and downloads. The various educational information in the digital information resources are one of the main content of educational information Design theory and practice of teaching resource database earlier, particularly in foreign countries such as Britain and the United States, teaching resource development of has formed a set of strict standards and the implementation of management models, characterized as followings: firstly, many foreign countries have established on information-oriented management portal and application mode of education resources, such as the United States portal of educational resources. The information platform is not guided by the specific resources, but the related data is stored in the database of educational resources on the network. Search for the user to provide information search and link oriented function.

Second, pay attention to the standardization of education resources. The process of resource library construction and the importance of the establishment of resource standardization are easy to find. Some official and unofficial organizations have set up a standard resource development and management standards to regulate the planning and development of the resource pool project, and promote the long-term development of the field. LRM, IEEE LTSC, LOM. Influential signs are LRM IEEE, LTSC LOM IMS model, etc.

Third, pay attention to the quality of resource development and the full utilization of resources. As the construction of teaching resources is a kind of consulting service, the actual work of scientific research and teaching institutions should be based on the service of this kind of information. Thus the information provided by the efficiency and quality to a higher request, regardless of the resource library building or post service is to customer demand oriented, forming a diversified modes of operation.

China education resources database construction began in Beijing Municipal Education Commission from 2005 starting to build Beijing Municipal Colleges and universities characteristic education resources construction project, Beijing Municipal Education Commission organizing the project, which requires the school to undertake the construction project to enhance service capabilities, enhancing the humanistic quality of college students, serving to enhance the learning oriented society's citizenship, and serve to the cultural and creative talents training, and serve the cultural strategy of Chinese cultural heritage. The theme is to organize the related resources around a certain theme, form a resource pool including text, picture, audio and video, and the subject index. In line with outstanding 
features, the use of the edge of the building and the principle is easy to use. Based on their existing resources and development planning from 2005 to 2010 in Beijing Municipal Education Commission, to participate in the construction of characteristic resources base of school with Beijing Institute of clothing technology, Beijing University of technology, Capital Institute of physical education, Academy of Chinese traditional opera, China Conservatory of music, Beijing Printing College, Beijing Dance Academy, Beijing Film Academy, Beijing Institute of civil engineering and architecture, Beijing Second Foreign Language Institute and other more than 10 municipal colleges and universities construct around 300 characteristic resources base.

During 2011, the characteristic education resource pool construction project subject resource including the film education, national music education, china dance education, education of traditional Chinese opera art, the culture of Chinese medicine education of 10 topics. In order to develop a certain number of subject resource package, on the characteristics of the resource on the basis of the original increase and a number of high-quality digital characteristic resource reserves. Beijing municipal colleges and universities special education resource library construction project in Colleges and universities sponsored by the education and Management Department of common domestic first regional characteristics of education resource library construction project. It has achieved good results, and other areas there is no research project of this scale. Some of the existing features of educational resources is studied by participate in the construction of individual institutions or individual disciplines, basically at an early stage, each unit project coverage is small, act of one's own free willingness, weak technical force, resources construction type of repetition, low degree of integration. Thus, the construction of library characteristic education resources in China will follow the "building and sharing in Beijing demonstration model the principle", establish the characteristics of educational resources corresponding with regional characteristics and cultural characteristics of the whole society, education and teaching service.

The ethnic universities and colleges face area, shortage of funds, paper documents for funding and the use of low rate fully reveals the ethnic characteristics of network education information resources. The various national colleges and universities have construction research on the construction of the characteristics education resources library has also been rapid development. Specification of national colleges of education resources, build project management platform and performance promotion platform and national colleges and characteristics of network education resources. On this basis, construction, integration and sharing application multiple theme resource kit, covering a number of professional disciplines, promote the sharing of resources characteristics, resource library in campus network operation and through establishment of characteristic resources base site open to the public. The Ethnic Universities and colleges teaching and scientific research of meticulous training of personnel and the broad masses of the people's humanistic quality cultivation, inheritance outstanding national traditional culture play an important promoting and supporting role.

\section{The Current Situation of Research on the Characteristics of Education Resource Base}

In recent years, research in the characteristics of educational resources is very active, with the Chinese CNKI database as the data source. The retrieval: key $=$ characteristic education resource library or special education resource or self education resource base, the retrieval time for 1990 to 2009 October, the removal of literatures were retrieved. Table 1 shows the 597 literatures in recent years the situation characteristics of education resource library research. From the table we can see that in twentieth century, research on the characteristics of educational resources is rarely, only 20 papers published in ten years, including 7 articles for the theoretical research of characteristic database construction, 4 for construction technique of the special education resource library, other research relatively, the main research direction to focus on research and technology research in theory, in the basic theoretical research and experimental operation.

In the initial stage of research from 2000 to 2004 with rapid growth of research papers, the number soared to 164, it is eight times the sum of the previous the 10 years in addition to the theoretical study of a large number of rich. After special feature database construction case study for an increase in the number on a field of a district characteristic education resources storehouse construction research development, the research has entered the in-depth study of the practice stage in 2005 to now is to accelerate the development trend, the volume before 5 years of more than 2 times.

Research in addition to the theory and it relates to copyright, quality control, education resource construction standards and quality evaluation shows that this stage study entered a stage of development. In general, a research paper on the characteristics of education resource library showed a rising trend, continued growth in the number of papers, research about characteristic education resources is getting more and more attention, the research in this field is also more and more deeply.

From Table 1, case study on the characteristics of education resource base theory research and a special subject 
database accounts for larger proportion accounted for $29.29 .82 \%$ and $33.16 \%$, for a total of $62.98 \%$, more than half of the total. Research is still the mainstream theory research and specific thematic database research. We should combine the theory and practice research about construction technology. The regional characteristics of the construction of educational resources database and some professional field range of characteristic construction about educational resources database and the number is not much, but was increasing trend.

Table 1. Characteristics database of research papers

\begin{tabular}{|c|c|c|c|c|c|c|c|c|c|c|c|c|}
\hline$\stackrel{\Xi}{\stackrel{\Xi}{2}}$ & $\begin{array}{l}\vec{D} \\
\stackrel{D}{E} \\
\vec{E}\end{array}$ & $\begin{array}{l}\text { के } \\
0 \\
0 \\
0 \\
0 \\
0 \\
\end{array}$ & 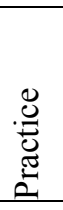 & $\frac{\overrightarrow{0}}{\overrightarrow{0}}$ & $\stackrel{\mathbb{J}}{\stackrel{2}{Z}}$ & 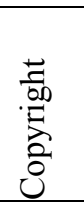 & 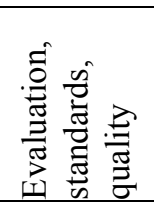 & 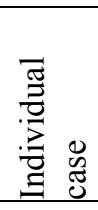 & $\begin{array}{l}\int_{0}^{3} \\
\sum_{0}^{0} \\
0 \\
0\end{array}$ & 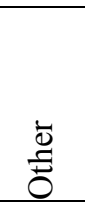 & $\stackrel{\bar{\pi}}{0}$ & 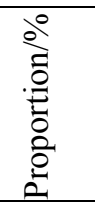 \\
\hline 2000 & 5 & 0 & 1 & 1 & 0 & 0 & 0 & 2 & 0 & 0 & 9 & 1.51 \\
\hline 2001 & 12 & 2 & 0 & 1 & 1 & 0 & 0 & 13 & 2 & 0 & 31 & 5.2 \\
\hline 2002 & 10 & 4 & 4 & 4 & 1 & 0 & 1 & 11 & 0 & 0 & 35 & 5.86 \\
\hline 2003 & 11 & 3 & 3 & 4 & 6 & 1 & 0 & 11 & 1 & 0 & 40 & 6.7 \\
\hline 2004 & 18 & 4 & 5 & 2 & 2 & 1 & 0 & 17 & 0 & 0 & 49 & 8.2 \\
\hline 2005 & 24 & 9 & 7 & 6 & 7 & 3 & 0 & 27 & 0 & 1 & 84 & 14.07 \\
\hline 2006 & 23 & 9 & 0 & 4 & 9 & 1 & 2 & 33 & 0 & 1 & 82 & 13.74 \\
\hline 2007 & 21 & 7 & 3 & 4 & 4 & 2 & 6 & 28 & 4 & 2 & 81 & 13.57 \\
\hline 2008 & 26 & 7 & 7 & 4 & 10 & 2 & 1 & 34 & 2 & 0 & 93 & 15.58 \\
\hline 2009 & 21 & 11 & 2 & 7 & 8 & 2 & 2 & 19 & 0 & 1 & 73 & 12.23 \\
\hline Total & 178 & 60 & 34 & 39 & 49 & 12 & 12 & 198 & 10 & 5 & 597 & \\
\hline Proportion/\% & 29.82 & 10.05 & 5.7 & 6.53 & 8.2 & 2.01 & 2.01 & 33.16 & 1.68 & 0.84 & & \\
\hline
\end{tabular}

Table 1 also shows that the exploration of the individual case study from the beginning of the 90s of the 20th century has been one of the focuses, in the 1990s both theory researches to later summary of theoretical research, the number of studies in each time period is relatively more steady. From Table 1, practicing research divided into technology research and field practice, the regional practice and general practice research part, the total number in Table 1 is not directly reflected.

\section{Overview of the Research on the Characteristics of Education Resources}

Through the analysis, the author argues that at present the research on characteristic education resources, particularly, in the characteristics of education resources storehouse construction is in necessity, construction principles, types of database, database technology, self building characterized library evaluation and copyright issues, respectively from several aspects of the overview.

\subsection{The Necessity of Building the Characteristics of Education Resource Library}

Construction characteristic education resource library can search the library collection and enrich the network resources, easy to searches. As the search engine is not in accordance with the professional division, it can not match the semantic content or meet the needs of professional search. Libraries of universities for Nationalities according to the service object of the school of professional information, construction of special education resources library, development representative characteristics of library education resources storehouse, more further in-depth search of information collection, information to meet the needs of the region and for readers provide in-depth literature information service.

The construction of digital library information to around the key discipline of the school, through special characteristic education resources construction of key subjects in the library service can work with information network environment. In favor of literature resources sharing library resources and on the basis of cooperation established characteristic digital database, and then through combined with the National Library of information to 
achieve complementary advantages. It can maximize play the potential and advantages of library. From the overall, the construction of universities for nationalities the literature information resource guarantee system, to meet the needs of teaching and scientific research.

Used in the rare books, digital conversion can be rare collection literature, meet the readers of the literature access requirements damage of precious books readers, and then to reduce the use of paper documents, improve the utilization rate of precious ancient books.

To improve the efficiency of the library, the national colleges and universities of professional settings is whether ethnic universities and colleges have stronger competition ability is one of the important factors. Thinking the needs of readers, construction of the Institute of professional characteristics and features of library collection of characteristic education resources library, it is conducive to the school teachers and students to master the latest science and technology give full play to the advantages of professional, to enhance the school's comprehensive competitiveness.

\subsection{Construction Principle}

The construction principle of characteristic education resources library is very important to improve the quality and the use value of the education resources storehouse. Many papers have a large space to explain this problem, but also a paper on the issue of special. The main points of view are as follows:

\subsubsection{Characteristics of the Collection Principle}

The selected topic of the education resources library should be fully reflected the characteristics of the library, which is the fundamental guarantee for the value of the resources of the education resources.

\subsubsection{Systematic Principle}

In the construction of characteristic education resource library, the comprehensive and systematic information is of great significance. In addition to printing characteristic literature digital outside, but also extensive collection of various other forms of information, after the completion of the building also information on the new continuous collection to make the characteristic education resources has use value and vitality.

\subsubsection{Feasibility Principle}

Construction of special education resources library must user needs to consider all aspects of the analysis of the established education resources storehouse construction after the completion of the resources rich degree, content system and the complete degree, digital processing technology and the ability, funding, personnel, experience, such as the development cycle, to ensure that the construction of educational resources database quickly and efficiently.

\subsubsection{Sharing Principle}

Literature collection standard, data description format, digital transformation, the use of the operating system and the main equipment, such as the need for keep good consistency and follow the unified standards and norms, make the education resources library is to share the good effect. CALIS "key subject network resources navigation education resource library" and other projects, the construction of the education resource pool of domestic characteristics to establish a model.

\subsubsection{The Principle of Regional Characteristics}

According to the regional principle, the establishment of a regional characteristic literature education resources library, its content in a certain region has the uniqueness and uniqueness. It can bring on College geographical location or other factors collection advantage, mining potential of literature information resources character characteristic education resources construction and principle of regional characteristics is conducive to the sharing of build, better play to the library.

\subsubsection{Serving to the Center and to the Market Oriented Principle}

The utilization rate of characteristic education resources is an important evaluation criterion for the construction of educational resources. The research on the construction of the characteristic education resource base should be based on the comprehensive understanding of the needs of readers, and select the information resources of the users' needs to focus on the development of the information resources. The library should take the market as the guidance to develop and construct the characteristic education resources storehouse, must carry on the construction according to the social development reality need, and causes the characteristic education resources storehouse resources to have the strong vitality. 


\subsubsection{The Practical and the Economic Principle}

Building the characteristic of education resource library is to meet the needs of the users literature information, and the utility is an important index to evaluate the value of an educational resource. Database must be a full investigation, the practical as an important principle. We should follow the principle of economy, the choice of platform construction to economical and practical, according to the resource type of self education resources database, data interface commonality, educational resources library release mode set equipment of the hardware, such as index considers. Choose platform of digital resources construction there are many, such as Tsinghua, Tongfang, TPI, Apabi of founder system etc. From the aspects of software and hardware and strive achieve the maximization of social benefits and economic benefits.

\subsection{Normalization and Standardization}

Most of the studies considered that standardization is an important problem in the construction of characteristic education resources. Digitization is the foundation of realizing information resources sharing, but the realization of information resource sharing needs to be standardized and standardized. In the construction to ensure standard description format, data search term standardization, the standardization of education resources storehouse construction standardization of software and hardware support must fully consider the requirements of the construction of the network in the future development of the. Standardization is the basis of realizing the sharing of resources between the education resource library and other educational resources.

\subsection{Study on the Aspects of Construction Technology}

Database technology a lot of research, generally at the main library building technology research including, ultra large scale content data management technology, multimedia technology, artificial intelligent XML Technology (Extended Markup Language), technology and digital media technology SQL Server(structured query language, structured query language) technology ASP (active server page, namely active server pages). In another word, technology IIS (Internet Information Services, namely Internet information services) released access technology (Microsoft relational educational resource management system) technology TRS (Text Retrieval System, that text retrieval system) and system.

\subsection{Research on the Evaluation of the Self Built Characteristic Education Resource Base}

Many scholars have carried out the research on the evaluation of the system of the education resources, but there is no uniform conclusion on the evaluation method of the characteristic education resource pool. Some people put forward to the content of educational resources database as the center to determine the evaluation index about making mathematics model of comprehensive evaluation, evaluation index include the content type of the literature, included age, data update time, the data source, data organization, retrieval functions and used by readers, through a weighted form to process mathematical model.

From the special education resource database system, the structure of several elements determine the evaluation indicators, including "data resources service platform", "description and indexing", "education resource database system platform", "infrastructure", "to promote the use", several aspects to determine the evaluation index of educational resources.

It is also suggested that the evaluation of characteristic education resources should be divided into 3 stages, the index are earlier, middle and later stage. Earlier index includes the feasibility and necessity of the construction. Medium-term index includes building hardware platform and educational resource database management system software, special education resource database retrieval performance, service scope and time, intellectual property and technical standard and the data standard. The later includes the renewal and improvement of the educational.

\subsection{Research on Copyright Issues}

Copyright of protection were plagued construction of characteristic library education resource database, which hinders the pace of characteristic construction of educational resources database construction. The characteristics of education resources library must attach great importance to the issue of intellectual property rights of the original. According to intellectual property of relevant laws, to avoid the copyright disputes on characteristic construction of educational resources database copyright issues. There are some kinds of representative point of view:

First, on the public domain literature, such as the ancient and rare books and more than 50 years protection period of literature, in the area of copyright protection of works and legal, regulations, news, which don't apply the works of copyright protection. The library can be on these types of public domain literature digital, income and self education resources database, does not belong to tort. In addition to the public domain literature, to other documents for digital 
should be handled carefully. Because, with the premise, and the literature don't infringed the author's copyright the non-public areas of literature.

Second, the purpose is to serve the school teaching and scientific research, its use is limited to the readers of the school, is not an infringement. Full text education resources library included the full text of books and periodicals, the use must be to restrict the user's IP address, for campus network users to use free of charge. The purpose of use is as a reference for the teaching and scientific research that through the education resources library is set to use the full right to limit, to outside users can retrieve bibliographic and view abstract. At present, China of educational resources library has no dedicated to specific provisions and legal protection clause. In this case, the permission set digital signature and digital watermark technology etc. The technical means to protect the educational resources library intellectual property information.

Third, aiming at the problem of property right of network information resources navigation database of thematic network navigation mainly, and through the hypertext links will focus on the network related information resources and order. In order to make the readers online access to distributed and stored in different websites service, the information resources that are scattered and disorderly, so as to improve the efficiency of the network information resources retrieval, does not belong to tort.

\section{Conclusion and Implications}

Overall, China Library Characteristic Construction of educational resources database is started and developed in the past 30 years. The research in view of the characteristics of the educational resources database construction nearly 10 years to began to perk up. But, the research has not been studied thoroughly, for special education resource database products market open up the realization of the economic value of method and other aspects for study. We should continue to be further expansion. And we believe that with the deepening of the research, the characteristics of education resources database construction will be more vigorous development, and be better of prospect about application and development.

\section{References}

Huang, X., \& Fu, P. (2007). The present situation, problems and Countermeasures of the construction of Chinese Library Characteristic Database. Information Science, 25(5).

Jin, M. (2001). Present situation and thinking of the construction of characteristic database in University Library. University Library and information, 3(11).

Li, Y. (2004). On the construction of characteristic database of University Library. The development of science and technology information and economy, 14(2).

Ling, S. (2009). On the construction of characteristic collection of Local University Libraries. Journal of Ankang University, 12(2).

Liu, B. (2008). Discussion on the construction of professional characteristic database in University Library. Science and technology information development and economy, 18(14).

Liu, H., \& Zhang, X. (2004). Characteristic database construction of University Library. Modern Information, (4).

Lu, H. (2009). Construction and consideration of characteristic database system. Jiangsu science and technology information, 2(7).

Ma, H. (2008). Some thoughts on the construction of characteristic database of University Library. Chinese Science \& Technology Expo, (23).

Song, P., \& Zhang, Y. (2009). New exploration on the construction of characteristic database of Local University Library. Jiangxi Library Journal, 39(3).

Tang, J. (2007). Discussion on some problems about the construction of characteristic database in University Library. Hebei Science and Technology Figure, 20(3).

Wang, X. (2008). On the construction of characteristic database of University. Scientific and Technological Information, (33).

Yuan, H. (2003). Intellectual property protection in the construction of Digital Library Information Resources. Journal of Shanghai Jiao Tong University, 37.

Zhang, H., \& Zhang, X. (2007). Review and Consideration on the construction of the CALLS key subject network resources navigation database during the fifteen period. Books and Information, (6)

Zhu, D. (2009). Research on construction technology of characteristic database in University Library. Inner Mongolia Science and Technology and Economy, (5). 